\title{
Structuring software anthropometric variables on CD Rom as a facilitator of the process of design of work situations
}

\author{
Sharinna Venturim Zanuncio ${ }^{\mathrm{a}}$, Simone Caldas Tavares Mafra ${ }^{\mathrm{b}, 1}$ Carlos Emílio Barbosa Antônio \\ Jugurta Lisboa Filho ${ }^{\mathrm{b}}$, Elza Maria Vidigal Guimarães ${ }^{\mathrm{b}}$, Vania Eugênia da Silva ${ }^{\mathrm{b}}$, Amaury Paulo de \\ Souza ${ }^{\mathrm{b}}$, Luciano José Minette ${ }^{\mathrm{b}}$ \\ a,b Department of Home Economics, Federal University of Vicosa, Avenue Peter Henri Holfs, s/n, Vicosa, State of \\ Minas Gerais, Brazil.
}

\begin{abstract}
The environment where everyday activities are developed, these should be appropriate and the individual who will execute them, for greater efficiency of their work and even if you feel safe, comfortable and satisfied when interacting with that space, expending less energy to this interaction. Given this context, this study aims to structure a software with the results obtained in the field, from anthropometric measure to subsidize the furniture industry in manufacturing of furniture, definition work situations, considering the different anthropometric measurements made between 2001 and 2010, using data from this sample of adults aged 18 to 65 years old and children between 6 and 11 years old. It was convenient to make the software with a site, only instead of staying on the Web has been recorded on CD Rom. Tests with the prototype allow navigation through the structure of the software. The data needed to implement the remaining modules were also raised. Issues related to system layout and usability of the interface also were not considered, because it is an initial prototype.
\end{abstract}

Keywords: anthropometry; anthropometry software, design space and securities

\section{Introduction}

This study is part of a research project still in progress, which aims at structuring a software with the results of the field, regarding the anthropometric measurements of adults and children, to support the furniture industry in the process furniture manufacturing, as well as the definition of work situations to the age of the study. It is worth nothing that the data presented here are partial and that the research and software development are still under development.

We are suppose that the adequacy of the work environment and leisure, and products that compose them, are developed by ergonomics studies, enabling more efficient planning of the individual.

According to Couto (1996, cited in Falcão, 2006) anthropometry measures human studies, which is an essential and important variable in determining a workplace, whereas work is detached from any action by the individual to meet a goal, be it survival, interaction with their environment daily, or even leisure.

This study allows the adequacy of workplace and home, as well as the products that compose it, the end user, ensuring greater welfare and quality of life and satisfaction with activities of daily work and family that are developed environments in which individuals experience daily.

\subsection{Purpose}

A software structure with the field results from anthropometric measure to subsidize the furniture industry manufacturing furniture, as well as the definition of work situations, considering the different

\footnotetext{
${ }^{1}$ Corresponding author: sctmafra@ufv.br
} 
anthropometric measurements made between 2001 and 2010 using the data for this sample of adults aged 18 to 65 years old and children between 6 and 11 years old.

\section{Literature review}

According to Frankel and Nordin (1980, cited in Hawk, 2006) describes the biomechanics of the human body movements and the forces that act on parts of this during everyday activities, considering this description to the laws of physics and engineering.

In this sense, the environment, where everyday activities are developed, these should be appropriate and the individual who will execute them, for greater efficiency of their work and even if you feel safe, comfortable and satisfied when interacting with that space, expending less energy for this interaction.

The suitability of securities to humans, it is necessary because the activities performed by them in day by day in different environments, and considering the time involved in them, can cause physical and psychological stress, if the environment and furniture are not adapted to them. Therefore, they fit the biotype of its mobile users is critical to ensure quality of life for this population.

Silveira (1979) explains that the biotypology differs from one individual to another, that due to external factors such as climate, nutrition, education and physical activity, and internal and genetics, heredity and pathogenicity, which can lead to constant changes of the human biotype .

Because of this and other factors involved, ergonomics is fundamental to the development of space projects and products. However, to achieve the expected efficiency for the same, it uses knowledge of anthropometry to fully capture and bring into the projects the physical variations of individuals.

Considering Iida (2005) ergonomics seeks to adapt work to human beings, while the occupational biomechanics is concerned with understanding this interaction, analyzing their body postures and the application of forces in the development of the interaction process. The author emphasizes that the inadequacy of products and work environments can affect the user's health, causing pain, muscle tension and physical fatigue, as mental strain.

In this regard, Smith and collaborators (2006) argues that ergonomics and anthropometry interact for the anthropometric dimensions and design products to spaces more appropriate and, therefore, adapted to use. What is reinforced by Silveira (1979) when he says that anthropometric measures to be effective, make it necessary that there be accuracy in the technique and the demarcation points for the measurement procedure, to ensure lower error coefficient, and data, if not equal to the real, present themselves as similar as possible.

Many countries worry about setting a standard for presentation of their products, but with the globalization of the economy, the products produced to meet the demand of certain countries have broken trade barriers and began to be marketed worldwide. This led him to move the view of the process of project design as a product that can be used by individuals from different countries, different ethnicities, regions and cultures. Therefore, it is necessary that the population of anthropometric variables are measured to ensure user comfort and safety at the same (IIDA, 2005).

Panero and Zelnik (2002) explain, size and body size are essential for adaptation ergonomic (ergofitling) and the man-machine system.

Since the environment where people and objects will be inserted must be compatible with the user and the activity for which it was designed so that it can be considered safe, comfortable, efficient, effective and help to integrate and ensure more and better quality life (OAK, 2006).

Projects should offer comfort, convenience and functionality for this, one must consider also the function of the body on that object (VISION 2006).

The Institute of Biomechanics of Valencia divides the science of measurements and dimensions of the human body (anthropometry) in structural dimensions (static) and functional dimensions (dynamic) (Silva and collaborators, 2006). And planning for the securities, according to Iida (2005) is still used anthropometry as the user remains in a stationary position or make a few moves during use.

Grandjean (1998), says that anthropometric measures are necessary to adapt the work environment and thus ensure an efficient working conditions for independent action of static or dynamic involved in the interaction. The author also refers to the variability of measures, due to the great diversity of biotypes human factor as the cause of problems in project design. Also points out that for some it is necessary to use the dimensions of taller individuals, for example, calculate the free space under the table, or measures of short people, to definition of reach to shelves. 
What can be seen in terms of design is that sometimes, we use average values of individuals, however, when extreme values are used, either the highest or lowest, these should be considered from the anthropometric survey, which allow the knowledge of the population and, consequently, allow the calculation of the percentiles ( 5 and 95) for later use in the project to fit a larger sample of the population. Generally, the percentiles are related to trying to meet close to $90 \%$ of this population.

Iida (2005) states that there are four types of measures for use in projects, which are: extreme measures - used to design the emergency exit, which require the use of higher values and to safeguard a large number of people using the site. Another example is the design of a wall cabinet, the measures used in this case must be those of smaller individuals, so they do not have trouble reaching them; projects for a population group - projects of this nature seek to achieve 5 to $95 \%$ the same, for example, cite projects car seat belts; projects developed for a particular type of individual although they are considered easier to adapt the output-user, these are high cost, and so are used in exceptional cases. However, it is used in projects of construction of orthopedic appliances, protheses, clothing and residential space; standard measures (medium type) - few people are considered as standard or average person, however, the use of the average for some projects will ensure a less physical stress for this group of the user population, compared the other projects wich use groups, for example, the mobile seat (IIDA, 2005).

Many studies have been designed to demystify the idea of the average individual, it is cited as an example to Panero and Zelnik (2002), where the authors do not mention the existence of the average man, ie the one that fits the 50th percentile and would represent half the user population surveyed in their study. The authors suggest that if you use measures of the average population for projects of furniture or space that would meet $50 \%$ of the population and the other $50 \%$ would be outside the process of using the space comfortably and securely. The authors argue, which is very important to ensure suitability for projects that anthropometric variables of the user population is set correctly to obtain adequate to the user.

The anthropometric parameters refer to a specific population and should not be used widely. Scholars argue that the topic is necessary to understand the characteristics of the user population to then determine the variables to be used. According to Iida
(1990, cited in Silva and collaborators, 2006), biotype differences, gender, age and ethnicity that may lead to different results in the characterization of anthropometric variables, and therefore should not be used interchangeably.

According to Petroski (2003) suggests that the ergonomic adjustments are used, so that the product is tailored to each user to avoid embarrassment during use. If this is not possible, you should use a representative sample of users of the product to be designed and measure the variables important for the production of it.

Iida (2005) in their studies have argued that inappropriate products can go through a corrective process (redesign), which seeks to adapt them to the user, making them more comfortable and safe, either by increasing or decreasing the height of a table or chair, or by using a ladder or scaffold that will assist in achieving a bench or cabinet. They are envisioning possibilities to reduce the imbalances of the product.

Iida (1991, cited Petroski, 2003) defines the work environment as the imaginary space that the individual uses to develop their activities. Often this space for daily activities, is small and needs to develop them while standing or sitting. This reality causes some members to be used with more intensity, and may cause physical damage to those who remain in these positions for long. It is therefore necessary to consider in designing projects, factors such as posture, intensity of activity books and clothing.

Recent studies have shown the dangers of working in a sitting position, nothing that "one third of patients admitted to hospital with deep vein thrombosis (DVT) were office workers who spend hours at a computer." "Data from the study are not yet available to the scientific community, but there is a publication of the prediction even in the New Zealand Medical Journal" (Work, 2007).

The study team mentioned "examined a sample of 62 people hospitalized with blood clots, and found that $34 \%$ had been sitting at their desk for long periods." The scholars state that DVT affects about 100,000 people and kills up to one thousand each year in Britain (WORK, 2007).

Besides the mentioned study, others show that during the activities in the sitting position, the body is supported by the skin covering the ischial bone, buttocks, and if this position is maintained for a very long period of time, the individual may be affected in severe pain in the muscles used to maintain this posture. To minimize fatigue on physical activity sitting, 
the seat should allow constant changes of position to mitigate the harmful effects of posture demanded (IIDA, 2005).

Other problems highlighted in the work is the frequent appearance seated pain in the neck when the user space has a slope greater than 30 degrees. Iida (2005) reinforces the idea that in this case is that the head tilt is 20 degrees. To achieve this the most comfortable position is necessary that the chair and table have a height suited to the user, reinforcing the importance of anthropometric studies to define values that offer comfort to the end user.

According to Petroski (2003) adults and children should not use the same size of furniture in the office or at school, however, at home, can share the same coach, for example, since this space there is greater flexibility to the use of the body and, consequently, changing attitudes required.

For the preparation of a product should consider the habits of those who use them and the environment where it is inserted, and the material to be used to manufacture it and the space where it will be located, so that all these aspects together, can promote the welfare during use (OAK, 2006).

Kendall (1995, cited in Reis, 2002) states that a high chair, for example, considering the stature of the user, generate discomfort for the support of the feet which will cause excessive pressure on the buttocks and thighs, resulting in pain in the region.

Reis (2002) adds that if the table height is too low compared to height, forces the individual maintain the back in wrong position, increasing the pressure over the lower back and neck, on the contrary, if the table is high, will force muscles of the shoulders and neck, because the arms will be out of the angle of 45 degrees, considered more comfortable.

Therefore, the use of average percentile principle would not meet the goal of comfort, health and safety in environments because it is believed that it is necessary to consider the extremes (5 and 95\%), considering the situations analyzed.

Panero and Zelnik (2002) said mean values aren't sufficient to determine the best anthropometric parameter, because the extreme dimensions are also important, and the situations experienced in the measurement data, for example, if the individual be dressed or footwear, modified this reality.

For the planning of an environment or product to meet certain population of users, one must consider the characteristics of it, as this will ensure greater comfort and safety, efficiency and effectiveness in development activities.
Considering the assumptions of anthropometry and ergonomics, which place the individual as central to all analysis and evaluation, and this study was developed and subsidize other data analysis as well, and increase the "state of the art" related to subject, object of this research.

\section{Methodology}

This study was carried out in Vicosa, State of Minas Gerais. Its development is due to the presence of the Federal University of Vicosa with a population of approximately 12,000 inhabitants, plus the city's population that according to preliminary data presented by the IBGE Census 2010 is around 70,923 inhabitants, numbering about 80,000 inhabitants.

Since the goal of software is to allow users to navigate among topics related to anthropometry and ergonomics as well as examination of the tables related to anthropometric variables measured, for purposes of this project was more convenient to make the software with only one site to instead of staying on the Web was recorded on a CD Rom.

Because it is a prototype was not emphasized in obtaining a final layout for the same. As any form of structured navigation and raised most of the content to be displayed.

\section{Results and discussion}

First, research was done to raise the content to be inserted into the software. The division presents the content index, preface, authors and knowledgments. This division is illustrated in Figure 1 is the homepage of the prototype. This page was obtained with the image editing tool Paint.

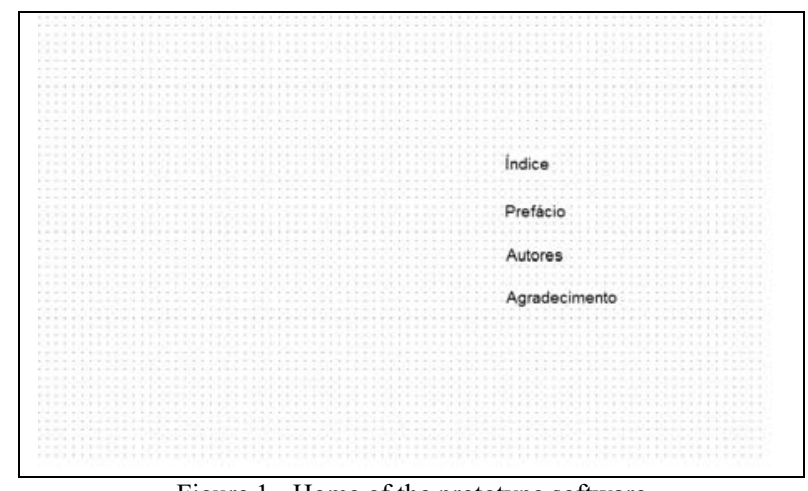

Figure 1 - Home of the prototype software 
Each item in Figure 1 is a link that directs to the page.

In the item in the index content was structured the way it can be seen in Figure 2. The items referring to the preface and thanks contain the corresponding content, structured by those responsible for anthropometric measurements. On the index page each item in yellow is a link that send the user to a page with relevant content. The default display of this content is basically the same, except for pages for the anthropometric tables.

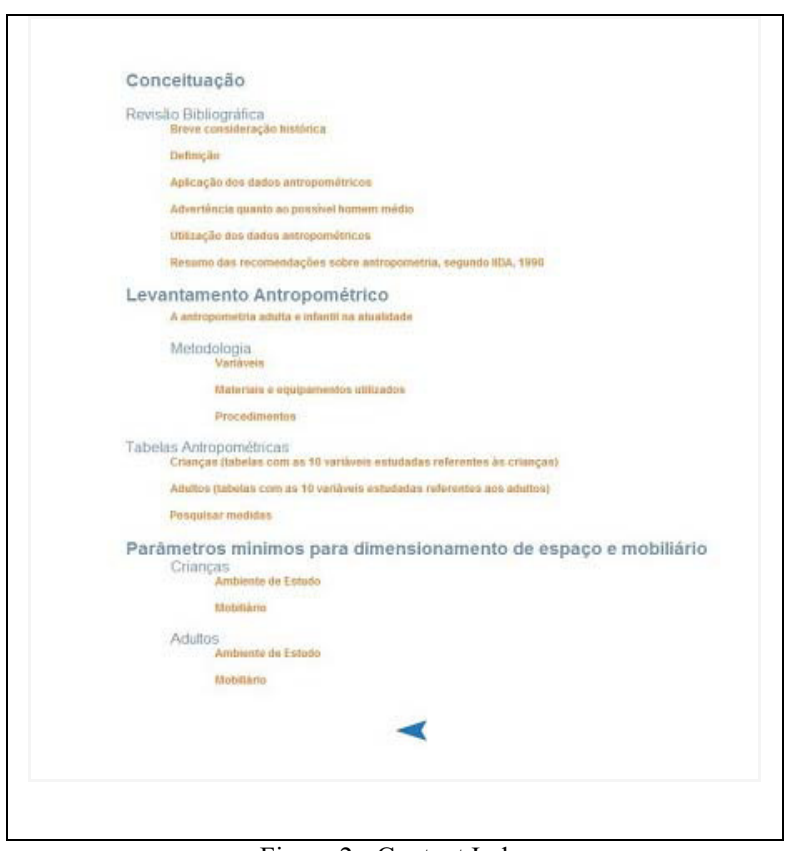

Figure 2 - Content Index

The item referring to the authors contains a page with the name of each author, in alphabetical order, according to Figure 3. Each name has a link that directs to another page where it appears the biography of each author.

On page represented in Figure 3 by clicking the name of the author the software directs you to a page with the biography of the authors as shown in Figure 4, taking as an example the author Amaury Paulo de Souza.

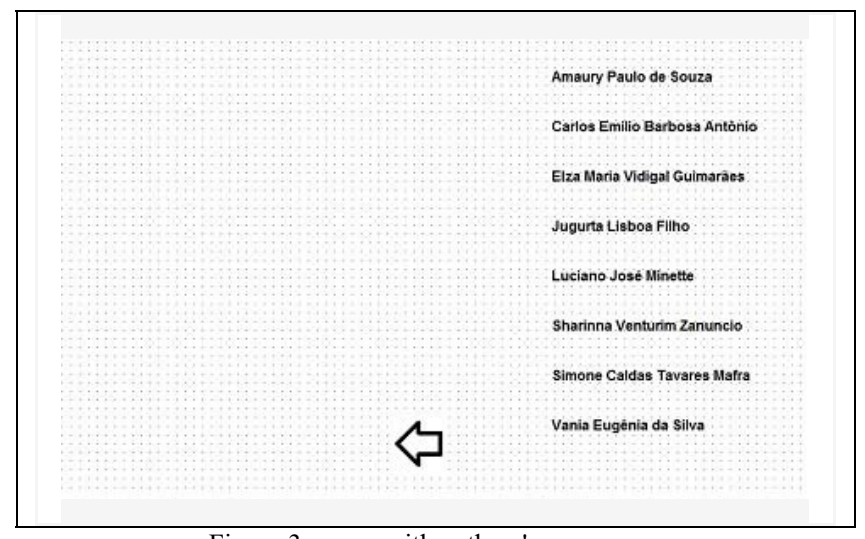

Figure 3 - page with authors' names

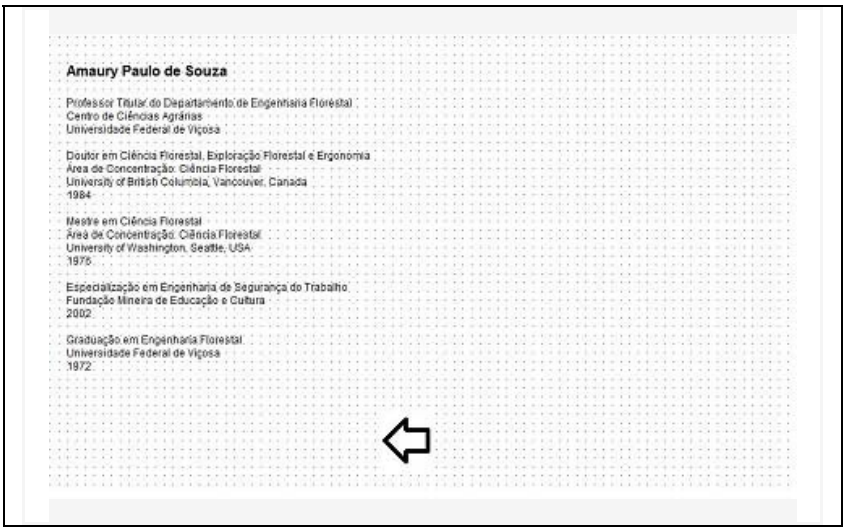

Figure 4 - Example of a biography author Amaury Paulo de Souza

The item concerning anthropometric tables for children and adults directs you to a page where they will be given the options of what tables you want to query, as shown in Figure 5. Clicking the link directs the software to a page that displays the desired table, according to the example in Figure 6, where you can view a table of thigh height adults.

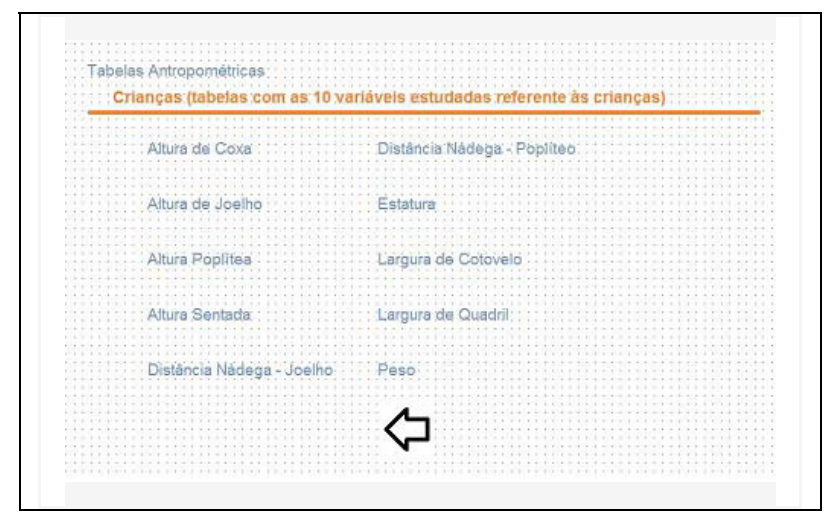

Figure 5 - Page to display the tables of children 


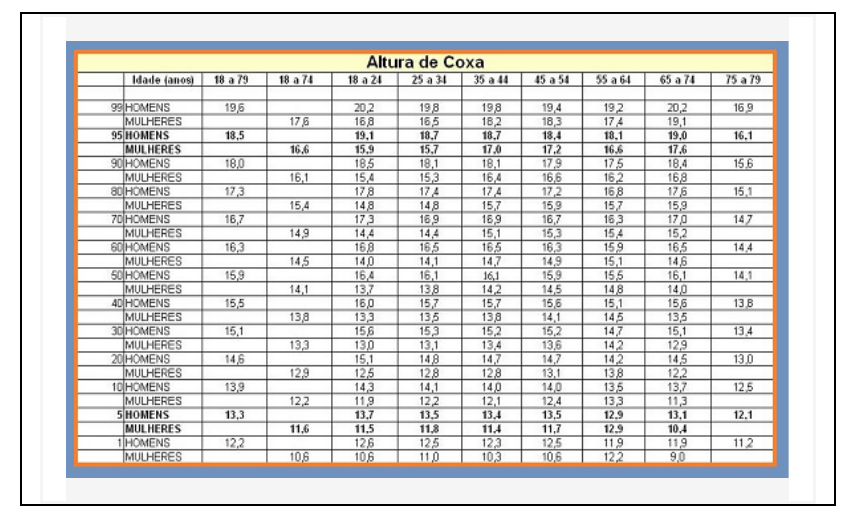

Figure 6 - Table Leg height for adults

Still in the index content at the Table Find the item Anthropometric measures with regard to the software module related to research to be carried in all the 10 anthropometric variables studied, used for the development of product designs, more specifically, furniture, or space.

For the development of this module was first made a study to relate the subset of anthropometric variables with each space or given mobile. The organization of the data was made as a tree (acyclic and connected graph) and is illustrated in Figure 7, for example a space power.

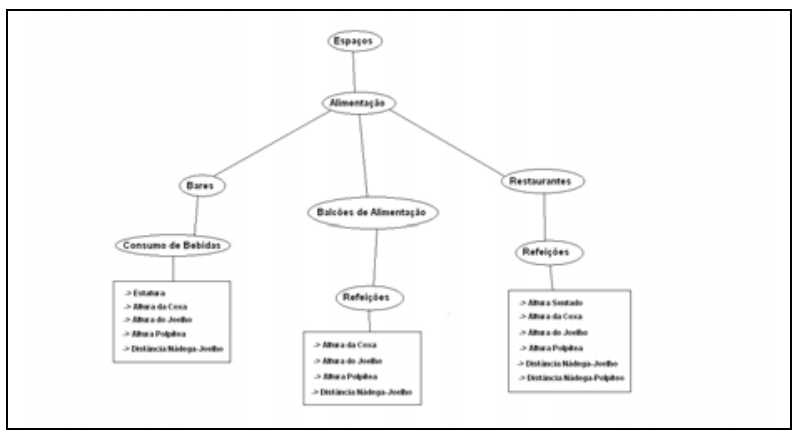

Figure 7: Tree model for development of space power

This representation was used for all types of spaces and furniture to be considered in the software. For the example in Figure 7 is that for the development of space-type cafeteria measures are required: height, height of the thigh, knee height, popliteal height and buttock-knee distance. This representation will serve to facilitate the implementation of the search module of the measures that will be made later.

The structuring of the page for the search module is not implemented yet. For purposes of this study, the concern was more related to structure any part of the navigation system and gather information so that the search is implemented in the future. However, he was made a model of how the page would be, which is illustrated in Figure 8.

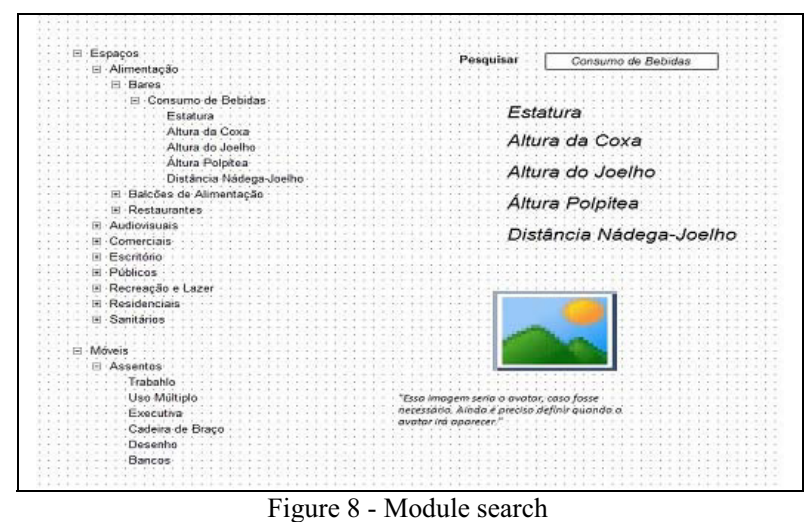

The research could be done by typing the name of the desired space in the "Search" and may also be a direct consultation in the left tree. The present image, below right, refers to a display of "Avatar" (virtual doll) with the measures indicated by the survey.

The editing of the images used to build the prototype of this system were all made in Paint tool.

\section{Results achieved}

Tests with the prototype allow navigation through the structure of the software. The data needed to implement the remaining modules were also raised.

Issues related to system layout and usability of the interface also were not considered, because it is an initial prototype.

\section{Conclusions and future work}

Given the perception of the importance of space and products used by individuals who care in their daily lives, and sometimes the inadequacy of anthropometric measurements used to structure the same, especially for the Brazilian population, it is believed that with the development of software, it can will, subsidize the furniture industry in manufacturing of furniture, as well as the definition of work situations, considering the different anthropometric measurements made between 2001 and 2010 for adults aged 18 to 65 years old and children between 6 to 11 years old, providing them 
with better quality of life and safety in their day by day.

As future work will be done the layouts of all system pages. This work will be done to improve the navigability and user interaction. Being well structured and implemented a layout for the search of variables.

\section{Acknowledgment}

This research receive the financial support of National Council for Scientific and Technological Development (NCSTD).

\section{References}

[1] Falcão, Franciane. Problematization of shtm. 2006. FUCAPI Manaus. Available at: <http://www.portal.fucapi.br>. Accessed: 10 November 2010.

[2] Grandjean, Etienne. Ergonomics Manual: adapting work to man. Trad. John Peter Stein. New York: Pergamon Press, 1998. 338p.

[3] IBGE - Brazilian Institute of Geography and Statistics. Census $2010.2010 . \quad$ Available at: $<$ http://www.ibge.gov.br/home/estatistica/populacao/censo20 10/default_uf.sht>. Accessed: 09 November 2010.

[4] Iida, Itiro. Ergonomic Design and Production. São Paulo: Edgard Blücher Ltda Ed, 2005. 465p.
[5] Oak, Young. Respect the values of men: the true scale of the design. Available at: <http://www.ricardobotelho.com.br $>$. Accessed: Nov 08. 2010.

[6] Panero, Julius; and Zelni, Martin. Sizing for Human Indoor. Translation: Regina Anita Di Marco.Barcelona: Publisher Gustavo Gili, 2002. 320p.

[7] Petroski, Edio Luiz. Anthropometry: Techniques and Standardization. 2nd ed. Rev. and ampl., Porto Alegre: Pallotti, 2003. 160p.

[8] Reis, Pedro Ferreira, Moro, Antonio Renato P.; Cruz, Roberto Moraes; Silva, Osni of Jacob, and Souza, Edson R. of. Using the average in the construction of school furniture and the illusion of comfort and health. In VII Latin American Congress on Ergonomics. I Brazilian Seminar on Integral Accessibility. XII Brazilian Congress on Ergonomics. RecifePE; Proceedings ... 2002. 4p.

[9] Silva, João Carlos Placido's Riccó; Paschoarelli, Luis Carlos; Spinosa, Rodrigo Martins de Oliveira. Anthropometric Digital Interface: public child, from preschool to elementary education. LEIDDI-PPGDI-FAAC. Bauru: Universidade Estadual Paulista, 2006.

[10]Silveira, Maria Tereza. Biometrics (Anthropometry and Biotypology). University Press of UFV, Viçosa-MG, 1979. 49p.

[11]WORK sitting increases risk of blood clots, says study. Available $<$ http://WWW.jornaldaciencia.org.br/imprimir.jpg?id=45243 >. Accessed: November 17, 2010.

[12]VISION East and the role of Interior Designer, focusing on the man, his size and habits. Available at: <http:// www.ricardobotelho.com.br>. Accessed: November 18, 2010. 